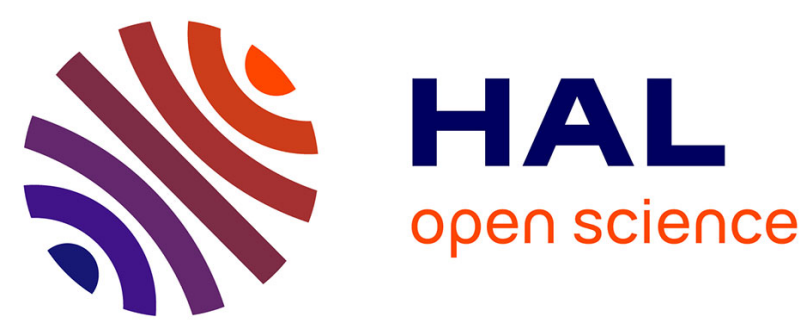

\title{
Phase I dose-escalation study of brostallicin, a minor groove binder, in combination with cisplatin in patients with advanced solid tumors
}

F. Caponigro, D. Lorusso, G. Fornari, C. Barone, M. Merlano, M. Airoldi, M. Schena, R. Macarthur, S. Weitman, M. G. Jannuzzo, et al.

\section{To cite this version:}

F. Caponigro, D. Lorusso, G. Fornari, C. Barone, M. Merlano, et al.. Phase I dose-escalation study of brostallicin, a minor groove binder, in combination with cisplatin in patients with advanced solid tumors. Cancer Chemotherapy and Pharmacology, 2009, 66 (2), pp.389-394. 10.1007/s00280-0091175-6 . hal-00552478

\section{HAL Id: hal-00552478 https://hal.science/hal-00552478}

Submitted on 6 Jan 2011

HAL is a multi-disciplinary open access archive for the deposit and dissemination of scientific research documents, whether they are published or not. The documents may come from teaching and research institutions in France or abroad, or from public or private research centers.
L'archive ouverte pluridisciplinaire HAL, est destinée au dépôt et à la diffusion de documents scientifiques de niveau recherche, publiés ou non, émanant des établissements d'enseignement et de recherche français ou étrangers, des laboratoires publics ou privés. 


\title{
Phase I dose-escalation study of brostallicin, a minor groove binder, in combination with cisplatin in patients with advanced solid tumors
}

\author{
F. Caponigro $\cdot$ D. Lorusso $\cdot$ G. Fornari $\cdot$ C. Barone $\cdot$ M. Merlano $\cdot$ M. Airoldi $\cdot$ \\ M. Schena $\cdot$ R. MacArthur $\cdot$ S. Weitman $\cdot$ M. G. Jannuzzo $\cdot$ S. Crippa $\cdot$ \\ F. Fiorentini $\cdot$ A. Petroccione $\cdot$ S. Comis
}

Received: 10 September 2009 / Accepted: 4 November 2009 / Published online: 22 November 2009

(C) Springer-Verlag 2009

\begin{abstract}
Purpose Brostallicin is a DNA minor groove binder which shows enhanced antitumor activity in cells which are resistant to several anticancer agents due to their high glutathione S-transferase (GST)/glutathione content. Phase I and II clinical trials of single-agent brostallicin have shown that myelotoxicity is the dose-limiting toxicity (DLT), while
\end{abstract}

F. Caponigro $(\bowtie)$

National Tumor Institute, Naples, Italy

e-mail: caponigrof@libero.it

D. Lorusso $\cdot$ C. Barone

Catholic University, Rome, Italy

G. Fornari

Valdese Hospital, Torino, Italy

M. Merlano

S. Croce e Carle Hospital, Cuneo, Italy

M. Airoldi

S. Giovanni Antica Sede Hospital, Torino, Italy

M. Schena

S. Giovanni Battista Hospital, Torino, Italy

R. MacArthur

Columbia University Research Pharmacy,

161 Fort Washington Ave., New York, NY 10032, USA

S. Weitman

MCS, 14358 N. Frank Lloyd Wright Blvd.,

Scottsdale, AZ 85260, USA

M. G. Jannuzzo · S. Crippa - A. Petroccione $\cdot$ S. Comis

Nerviano Medical Sciences, Nerviano, Italy

F. Fiorentini

Accelera, Nerviano, Italy hints of antitumor activity were mainly observed in soft tissue sarcoma. Preclinical studies showing a more than additive antitumor effect of the cisplatin-brostallicin combination paved the way to clinical combination studies. In particular, we set up the first clinical combination study of brostallicin and cisplatin in patients with advanced solid tumors. This study was to be followed by a phase II study in patients with recurrent squamous cell carcinoma of the head and neck (SCCHN).

Methods Escalating doses of brostallicin were administered in combination with a fixed dose of cisplatin $(75 \mathrm{mg} /$ $\mathrm{m}^{2}$ ) in patients with recurrent or metastatic advanced solid tumors who had previously received a cumulative dose of cisplatin not higher than $475 \mathrm{mg} / \mathrm{m}^{2}$. The recommended dose of brostallicin was expanded in order to have a better estimate of antitumor activity and to better define the safety profile of the combination.

Results Twenty-one patients were treated. Two DLTs (grade 3 fatigue and febrile neutropenia) were observed at dose level 3 (brostallicin $9 \mathrm{mg} / \mathrm{m}^{2}$ ). Dose level 2 (brostallicin $7 \mathrm{mg} / \mathrm{m}^{2}$ and cisplatin $75 \mathrm{mg} / \mathrm{m}^{2}$ ) was recommended for future phase II studies. Main toxicity was hematologic; in fact, only 1 patient out of 21 did not develop neutropenia and only 2 patients did not have thrombocytopenia. Grade 3-4 neutropenia was observed in $90.5 \%$ of patients, grade 3-4 thrombocytopenia in $38.1 \%$, grade $3-4$ anemia in $23.8 \%$. The cycle 1 nadir (ANC $<500 \times 10^{9} / \mathrm{L}$ ) for neutrophils was Day 14 (median; range 11-17) with recovery to an ANC of $>1,5003.5$ days after nadir (median; range 2-4) at dose level 3. The cycle 1 nadir (median of $51,000 \times 10^{9} /$ L) for platelets occurred on Day 13 (median; range 10-15) with recovery to a platelet count of $>100,0004$ days after nadir (median; range 2-8). No objective responses were observed, but seven patients had a long lasting ( $>18$ weeks) stable disease. 
Conclusions Further studies of the combination of brostallicin and cisplatin are warranted.

Keywords Brostallicin · Cisplatin · Phase I - Solid tumors

\section{Introduction}

Brostallicin (PNU-166196A) is an unique alpha-bromoacrylic DNA minor groove binder which requires glutathione S-transferase (GST) and glutathione (GSH) for activation. In this regard, brostallicin has the peculiarity of showing enhanced antitumor activity in cells which are resistant to other anticancer agents, including cisplatin, due to their high glutathione GST/GSH content [1].

Brostallicin has been tested in phase I clinical trials with two different schedules. In particular, at Vanderbilt-Ingram Cancer Center, a phase I study of brostallicin on days 1, 8, 15 , every 28 was carried out. In this study, neutropenia and thrombocytopenia qualified as dose limiting toxicities (DLT); the maximum tolerated dose (MTD) was $2.4 \mathrm{mg} / \mathrm{m}^{2} /$ week. No evidence of antitumor activity was reported in this study, but five patients had stable disease after two cycles of treatment [2]. Thrombocytopenia and neutropenia qualified also as DLTs in the Dutch study evaluating brostallicin administered intravenously every 3 weeks in adult patients with metastatic solid tumors. The maximum tolerated dose and recommended dose for phase II evaluation were set at $10 \mathrm{mg} / \mathrm{m}^{2}$. Pharmacokinetic analysis did not show significant brostallicin accumulation following repeated administration. Some evidence of clinical activity was observed in gastrointestinal solid tumors (GIST), one patient achieving a partial response per the investigator [3].

Preclinical data showing the activity of brostallicin in cisplatin-resistant cell lines have been published [4]. Furthermore, the cisplatin-brostallicin combination has been tested in the human colon carcinoma (HCT-116) model transplanted in nude mice. Two treatment schedules were tested in this study: cisplatin followed $48 \mathrm{~h}$ later by brostallicin, and brostallicin followed by cisplatin. In keeping with the increased GST activity observed after treatment with cisplatin, the cisplatin/brostallicin interaction was sequence-dependent, leading to a more than additive antitumor effect, without additional toxicity, only when cisplatin was given before brostallicin [4].

The above results have paved the way to evaluate the clinical combination of brostallicin and cisplatin in a phase I study. In particular, we set up the first clinical combination study of brostallicin and cisplatin in patients with advanced solid tumors. This study was to be followed by a phase II study in patients with recurrent/metastatic Squamous Cell Carcinoma of the Head and Neck (SCCHN).

\section{Patients and methods}

\section{Patient selection}

Inclusion criteria common to both parts of the study were: age of at least 18 years; Eastern Cooperative Oncology Group (ECOG) performance status of 0 or 1 ; life expectancy of at least 3 months; adequate baseline organ function defined as absolute neutrophil count $\left(\right.$ ANC) $\geq 1,500 \times 10^{9} / \mathrm{L}$, platelets $\geq 100,000 \times 10^{9} / \mathrm{L}$, hemoglobin $\geq 10 \mathrm{~g} / \mathrm{dL}$, liver transaminases $\leq 3 \times$ upper limits of normal (ULN) (in case of liver metastasis $\leq 5.0 \times \mathrm{ULN}$ ), total serum bilirubin $\leq$ $1.5 \times \mathrm{ULN}$, serum albumin $\geq 3 \mathrm{~g} / \mathrm{dL}$, serum creatinine $\leq$ $1.25 \times \mathrm{ULN}$, alkaline phosphatase $\leq 2.5 \times \mathrm{ULN}$; negative serum pregnancy test; signed written informed consent and adequate treatment compliance.

The main specific inclusion criteria in the dose escalation part of the study included histologic or cytologic confirmation of any squamous cell carcinoma subsequently amended to all tumors; recurrent/metastatic disease after failure of one or more standard therapy lines and a cumulative dose of cisplatin not higher than $475 \mathrm{mg} / \mathrm{m}^{2}$, prior to enrollment. The main specific inclusion criteria for phase II were histologic or cytologic confirmation of SCCHN, evidence of recurrent disease after surgery with post-operative radiotherapy not suitable for local therapy; at least one bidimensional or unidimensional measurable target lesion; patient relapse after prior concomitant chemo-radiotherapy or neoadjuvant chemotherapy provided the previous cisplatin cumulative dose was not higher than $475 \mathrm{mg} / \mathrm{m}^{2}$, and disease free survival (DFS) was at least 6 months.

The study was sponsored by Nerviano Medical Sciences and was approved by the Ethics Committee of each participating center. Written informed consent was obtained from each patient before registration.

\section{Treatment plan}

Cisplatin was administered with a standard hydration protocol at the fixed dose of $75 \mathrm{mg} / \mathrm{m}^{2}$. Brostallicin was administered immediately after cisplatin post-hydration at the initial dose of $5 \mathrm{mg} / \mathrm{m}^{2}$ over $10 \mathrm{~min}$. The two drugs were administered on day 1 of a 21-day cycle. The 3-week cycle schedule of administration is frequently used for cisplatin and brostallicin as single agents and was considered likely to be suitable for the co-administration. Cisplatin was given before brostallicin according to preclinical findings, and the two drugs were given on the same day also for logistic reasons. The dose escalation scheme is detailed in Table 1. DLT was defined as grade 4 neutropenia lasting at least 7 days; febrile neutropenia; grade 4 thrombocytopenia lasting at least 7 days; grade 3 thrombocytopenia associated with bleeding; grade $\geq 3$ nausea or vomiting despite maximal 
Table 1 Brostallicin dose escalation scheme

\begin{tabular}{lll}
\hline Dose Level & \multicolumn{2}{l}{ Dose } \\
\cline { 2 - 3 } & cDDP $\left(\mathrm{mg} / \mathrm{m}^{2}\right)$ & Brostallicin $\left(\mathrm{mg} / \mathrm{m}^{2}\right)$ \\
\hline-1 & 75 & 4.0 \\
1 (starting dose) & 75 & 5.0 \\
2 & 75 & 7.0 \\
3 & 75 & 9.0 \\
\hline
\end{tabular}

antiemetic therapy; any grade 3 or 4 extrahematologic toxicity; ineligibility for re-treatment after a 2-week delay. Three patients were to be enrolled at dose level 1 . If $0 / 3$ of these patients had DLT, then the dose was to be escalated to the next higher level in the three subsequent patients. If $1 / 3$ patient experienced DLT, then three more patients were to be accrued at the same dose level. If none of these three additional patients had DLT, the dose was to be escalated in subsequent patients. If at least two patients (either out of three or out of six) experienced DLT, the MTD was considered to have been exceeded and three further patients were to be treated at the immediately lower dose. A single dose de-escalation of brostallicin was allowed from the starting dose in case level 1 had been found to exceed the MTD. If two or more patients out of the three or six treated at level -1 encountered DLT, the brostallicin/cisplatin combination was to be abandoned. The first two patients in each cohort were to be observed for 22 days after treatment before enrolment of subsequent patients at the same dose level. The last patient in each cohort was to be observed for 22 days after treatment or until recovery before enrolment of subsequent patients at the next higher dose level. Once the MTD had been identified, additional patients with SCCHN were to be enrolled at this dose level to have a better estimate of the antitumor activity of the combination.

Patient evaluation

Enrolment patients were evaluated by complete history, physical examination, performance status recording, ECG, complete blood cell count (CBC), serum chemistries, urineanalysis, chest radiograph and total body computed tomography (CT) scan or magnetic resonance imaging (MRI). Other exams were performed in presence of clinical indication. Patients were monitored throughout the treatment by weekly clinical examination, toxicity assessment, CBC counts. Other laboratory tests were performed before the start of each cycle. Response was assessed according to modified WHO criteria. Toxicities were graded by the National Cancer Institute Common Terminology Criteria for Adverse Events (NCI CTCAE) version 3.0.
Statistical methods

The standard " $3+3$ " design was used for the phase I study. For the phase II study, the sample size was to be calculated according to the Simon Minimax two-stage design [5].

The primary endpoint of the dose escalation study was the identification of DLT(s), whereas the Objective Response (OR) rate measured according to WHO criteria was the primary endpoint for the phase II portion. Time to progression was calculated as the time interval from treatment start to progression or death due to cancer or unknown causes.

\section{Pharmacokinetics}

Plasma concentrations of brostallicin, total platinum and free cisplatin were determined at $0-48 \mathrm{~h}$ during cycle 1 in six patients participating in the dose escalation phase and receiving the MTD, aimed at calculation of brostallicin and cisplatin pharmacokinetics parameters at the recommended phase II dose. No pharmacodynamic studies were performed. The results of the pharmacokinetic analysis for the combination will be reported briefly here.

\section{Results}

Patient characteristics

Between July 2005 and February 2007, 22 patients were enrolled in this study, but only 21 received study medication. Phase II study was not carried out because of slow accrual of the target population observed to the phase I study before extending the inclusion to all solid tumors. Median age was 59.3 years; 11 patients were males; performance status was 0 in the majority of patients; squamous cell carcinoma of the head and neck was the primary diagnosis in 11 out of 21 patients. Two-thirds of patients had metastatic disease, while local recurrences accounted for the remaining cases; thirteen patients had stage IV disease. The characteristics of the treated patients are detailed in Table 2.

\section{Dose escalation results}

Twenty-two patients were recruited in total and all but one were treated with at least one dose of brostallicin-cisplatin. Dose escalation was stopped at level 3 with two DLTs observed during cycle 1 , namely grade 3 fatigue and febrile neutropenia. Dose level 2 was then expanded to a total of ten patients to better define the safety profile at the recommended phase II dose and the PK characteristics. The total population of 21 treated patients received 88 treatment 
Table 2 Characteristics of treated patients $(n=21)$

\begin{tabular}{|c|c|}
\hline & $n=21$ \\
\hline \multicolumn{2}{|l|}{ Age (years) } \\
\hline$<65$ & 13 \\
\hline$\geq 65$ & 8 \\
\hline \multicolumn{2}{|l|}{ Sex } \\
\hline Male & 11 \\
\hline Female & 10 \\
\hline \multicolumn{2}{|l|}{ Primary diagnosis } \\
\hline SCCHN & 11 \\
\hline Cervical cancer & 5 \\
\hline Endometrial cancer & 2 \\
\hline Leiomyosarcoma & 2 \\
\hline Undifferentiated hypopharynx & 1 \\
\hline \multicolumn{2}{|l|}{ Disease status at admission } \\
\hline Metastatic & 14 \\
\hline Local recurrence & 7 \\
\hline \multicolumn{2}{|l|}{ Metastatic site } \\
\hline Lung & 7 \\
\hline Lymph node & 4 \\
\hline Liver & 3 \\
\hline Bone & 1 \\
\hline Other & 4 \\
\hline \multicolumn{2}{|l|}{ Current disease stage } \\
\hline II & 2 \\
\hline III & 4 \\
\hline IV & 13 \\
\hline Other & 2 \\
\hline \multicolumn{2}{|c|}{ Number of prior systemic chemo-regimes } \\
\hline 0 & 3 \\
\hline 1 & 7 \\
\hline 2 & 8 \\
\hline$>2$ & 3 \\
\hline \multicolumn{2}{|l|}{ Previous therapy with cisplatin } \\
\hline Yes & 12 \\
\hline No & 9 \\
\hline
\end{tabular}

cycles (25 at dose level 1, 46 at dose level 2, and 17 at dose level 3). A median of four cycles of treatment were administered (range 1 to 8 ). Median brostallicin dose intensity was $2.1 \mathrm{mg} / \mathrm{m}^{2} /$ week ( $87.4 \%$ of the planned). Median value of cisplatin dose intensity was $22.8 \mathrm{mg} / \mathrm{m}^{2} /$ week $(91.3 \%$ of the planned dose).

\section{Toxicity}

All treated patients had at least one adverse event, most frequently hematologic. Neutropenia was observed in $95.2 \%$ of patients, thrombocytopenia and anemia in $57.1 \%$, each, febrile neutropenia in 9.5\%. In particular at dose level 1, neutropenia and anemia were reported in $80 \%$ of patients each, thrombocytopenia in $60 \%$; at dose level 2 , neutropenia occurred in $100 \%$ of patients, thrombocytopenia and anemia in $40 \%$ of patients each. At dose level 3, neutropenia occurred in $100 \%$ of patients, thrombocytopenia in $83.3 \%$ and anemia in $66.7 \%$. The cycle 1 nadir $\left(\mathrm{ANC}<500 \times 10^{9} / \mathrm{L}\right)$ for neutrophils was on Day 14 (median; range 11-17) with recovery to an ANC of $>1,500$ 3.5 days after nadir (median; range 2-4) at dose level 3 . The cycle 1 nadir (median of $51,500 \times 10^{9} / \mathrm{L}$ ) for platelets occurred on Day 13 (median; range 10-15) with recovery to a platelet count of $>100,0004$ days after nadir (median; range 2-8). Main extra-hematologic toxicities were nausea (52.4\% of patients), vomiting (33.3\%), constipation (28.6\%), and diarrhea (14.3\%). General disorders were reported in $52.4 \%$ of patients and included asthenia, fatigue, and fever. Two patients died during the study observation period, 11 and 42 days after last treatment dose, respectively. The reasons for these events were sudden death following acute myocardial infarction that was not considered as drug-related, and progressive disease, respectively. The sudden death was observed in a 67-yearold white male with medical history of aortic stenosis and atherosclerosis. In particular, sudden death was observed a few days after acute inferior myocardial infarction, which, in turn had been preceded by acute thoracic pain after which cisplatin had been withdrawn. The reporting physician considered that there was not a reasonable possibility that the event was related to brostallicin. On the other hand, the heavy hydration required for cisplatin could have been considered as a contributory factor. Serious adverse events were reported in six other patients; in particular, four patients had a hematological serious adverse event, one patient had leg fracture and one patient had grade 4 diarrhea and grade 3 renal failure. This last event occurred in a 54-year-old white female with recurrent, bladder infiltrating, cervical cancer with and hydroureteronephrosis. The investigator stated that diarrhea was possibly related to brostallicin and probably related to cisplatin; creatinine increase was probably triggered by dehydration due to diarrhea and was assessed as unrelated to brostallicin. Laboratory tests showed significant hematologic toxicity in most patients. Only 1 patient out of 21 did not develop neutropenia and only 2 patients did not have thrombocytopenia. Grade 3-4 neutropenia was observed in $90.5 \%$ of patients, grade $3-4$ thrombocytopenia in $38.1 \%$, grade $3-4$ anemia in $23.8 \%$. Grade 3-4 blood chemistry abnormalities included grade 3 elevation in bilirubin in 1 patient, grade 3-4 sodium increase in $28.6 \%$, and grade 3 magnesium increase in $21.1 \%$ of patients, respectively. Bilirubin and magnesium abnormalities were seen at second cycle or later, while sodium abnormalities were observed either at cycle 1 or at following cycles. ECG was recorded at baseline in 18 
patients and repeated subsequently in 14 cases. No changes were recorded in all but two patients, who had acute myocardial infarction, and non-specific conduction delay, respectively. Toxicities are detailed in Tables 3 and 4.

\section{Response}

All but one patient had at least one tumor assessment after treatment start. There were no documented confirmed CR

Table 3 Frequency distribution of hematological parameters by maximum CTC grade at cycle 1 and at following cycles

\begin{tabular}{|c|c|c|c|c|c|c|c|}
\hline \multirow[t]{2}{*}{ Cycle } & \multirow{2}{*}{$\begin{array}{l}\text { Max CTC } \\
\text { grade }\end{array}$} & \multicolumn{2}{|c|}{ Hemoglobin } & \multicolumn{2}{|c|}{ Platelets } & \multicolumn{2}{|c|}{ Neutrophils } \\
\hline & & $n$ & $\%$ & $n$ & $\%$ & $n$ & $\%$ \\
\hline \multirow[t]{6}{*}{1} & 0 & 2 & 9.5 & 5 & 23.8 & 2 & 9.5 \\
\hline & 1 & 15 & 71.4 & 8 & 38.1 & - & - \\
\hline & 2 & 3 & 14.3 & 5 & 23.8 & 4 & 19.0 \\
\hline & 3 & 1 & 4.8 & 2 & 9.5 & 2 & 9.5 \\
\hline & 4 & - & - & 1 & 4.8 & 13 & 61.9 \\
\hline & Total & 21 & 100.0 & 21 & 100.0 & 21 & 100.0 \\
\hline \multirow[t]{6}{*}{$>1$} & 0 & 1 & 1.6 & 26 & 40.6 & 4 & 6.3 \\
\hline & 1 & 28 & 43.8 & 19 & 29.7 & 7 & 10.9 \\
\hline & 2 & 28 & 43.8 & 8 & 12.5 & 8 & 12.5 \\
\hline & 3 & 5 & 7.8 & 7 & 10.9 & 27 & 42.2 \\
\hline & 4 & 2 & 3.1 & 4 & 6.3 & 18 & 28.1 \\
\hline & Total & 64 & 100.0 & 64 & 100.0 & 64 & 100.0 \\
\hline
\end{tabular}

Table 4 Frequency of treatment emergent extrahematologic toxicities occurred in $\geq 10 \%$ of patients by maximum CTC grade $(n=21)$

\begin{tabular}{llllll}
\hline \multicolumn{5}{c}{ Maximum CTC grade } \\
\cline { 2 - 6 } & 1 & 2 & 3 & 4 & $\begin{array}{l}\text { Any grade } \\
n(\%)\end{array}$ \\
& $n(\%)$ & $n(\%)$ & $n(\%)$ & $n(\%)$ & $n(1152.4)$ \\
Nausea & $3(14.3)$ & $8(38.1)$ & - & - & $7(33.3)$ \\
Vomiting & $2(9.5)$ & $4(19.0)$ & $1(4.8)$ & - & $6(28.6)$ \\
Constipation & $3(14.3)$ & $2(9.5)$ & $1(4.8)$ & - & $3(14.3)$ \\
Diarrhea & - & $2(9.5)$ & - & $1(4.8)$ & $4(19.0)$ \\
Asthenia & $1(4.89)$ & $1(4.8)$ & $2(9.5)$ & - & $4(19.0)$ \\
Pyrexia & $3(14.3)$ & $1(4.8)$ & - & - & $4(19.0)$ \\
Fatigue & $1(4.8)$ & $1(4.8)$ & $1(4.8)$ & $1(4.8)$ & 4 \\
\hline
\end{tabular}

or PR as best response. Confirmed SD of $\geq 18$ week duration was seen as best response in seven $(7 / 20 ; 35 \%)$ patients, including three patients treated at dose level 1 , three patients treated at dose level 2, and one patient treated at dose level 3. In these patients confirmed SD lasted from 18.4 to 31.3 weeks, with a median value of 27.3 weeks. Seven patients showed SD of less than 18 weeks duration as best response (total of $70 \%$ of patients with SD), while $\mathrm{PD}$ was reported as best response in the six remaining assessed cases.

Out of seven patients with stable disease of $\geq 18$ weeks, five had at least one prior systemic platinum-based chemotherapy regimen. Of these five patients, one patient had a best response of complete response to previous platinumbased chemotherapy, two patients had a partial response, one had stable disease, and one had a best response to prior platinum-based chemotherapy of progressive disease (Table 5). In addition, all of the patients [5] who had prior platinum-based chemotherapy and stable disease on the brostallicin-cisplatin combination remained on the current regimen longer than prior platinum-based therapies.

\section{Pharmacokinetic results}

The pharmacokinetic (PK) profiles of brostallicin, total platinum and free cisplatin were investigated at cycle 1 in four patients treated at dose level 1 , in six patients treated at dose level 2, and in two patients treated at dose level 3 . Brostallicin Cmax average values showed a dose increase from $455 \mathrm{ng} / \mathrm{mL}$ at $5 \mathrm{mg} / \mathrm{m}^{2}$ to $1,570 \mathrm{ng} / \mathrm{mL}$ at $7 \mathrm{mg} / \mathrm{m}^{2}$ to $1,525 \mathrm{ng} / \mathrm{mL}$ at $9 \mathrm{mg} / \mathrm{m}^{2}$ (Fig. 1). No difference between dose levels was seen for $t_{1 / 2}(0.8,0.7$, and $0.8 \mathrm{~h}$ at the 3 dose levels, respectively). For two patients, the investigation of the disposition of total platinum and brostallicin was also performed on cycle 2 indicating no significant difference in PK parameters of the compound in the two cycles.

\section{Discussion}

Minor groove binders represent a new class of anticancer agents whose DNA sequence specificity may lead to a high selectivity of action [6,7]. The initial compounds of this
Table 5 Duration of treatment with brostallicin/cisplatin compared to prior cisplatin-based therapy in five patients with long-lasting SD

\begin{tabular}{llll}
\hline $\begin{array}{l}\text { Brostallicin } \\
\text { dose }\left(\mathrm{mg} / \mathrm{m}^{2}\right)\end{array}$ & $\begin{array}{l}\text { Best response to prior } \\
\text { platinum-based } \\
\text { therapy }\end{array}$ & $\begin{array}{l}\text { Duration of treatment } \\
\text { with prior platinum-based } \\
\text { therapy (weeks) }\end{array}$ & $\begin{array}{l}\text { Duration of treatment } \\
\text { with brostallicin-cisplatin } \\
\text { (weeks) }\end{array}$ \\
\hline 5 & PR & 12.9 & 27.3 \\
7 & CR & 19.3 & 21.1 \\
& PR & 19.9 & 27.6 \\
9 & SD & 15.7 & 21.1 \\
& PD & - & 31.0
\end{tabular}




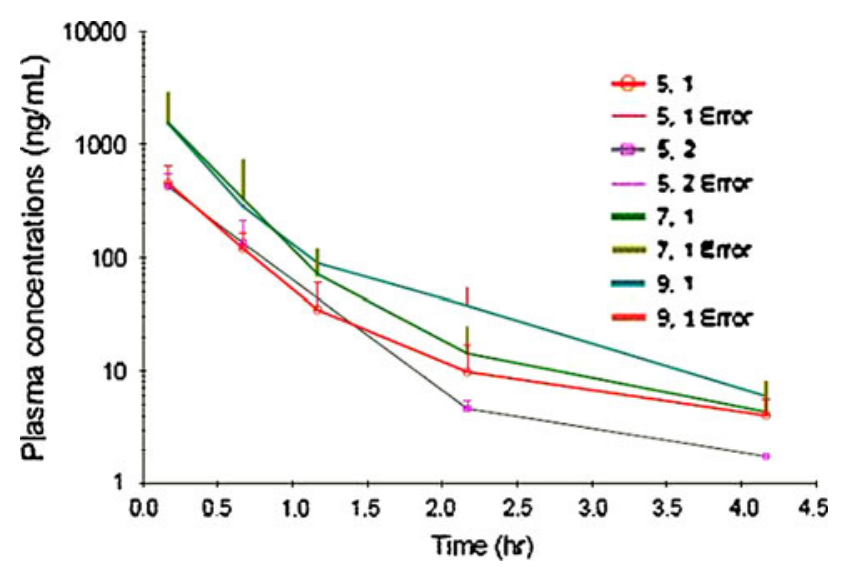

Fig. 1 Average brostallicin plasma level \pm SD at cycle 1 and by dose level

class, in spite of the exciting activity shown in preclinical models, did not undergo complete clinical development due to their severe myelotoxicity [8-11]. Brostallicin is a newer minor groove binder, which was selected for clinical development because of its improved therapeutic index (outstanding clinical activity and a favorable toxicity profile) in preclinical models [1]. Biochemical studies have supported the idea that brostallicin is particularly active in presence of high GSH/GST levels, which may be induced by pretreatment with other anticancer drugs and can play a role in tumor resistance to several anticancer agents including cisplatin. The notion that tumor cells frequently display increased levels of GSH and/or GST has further increased the appeal of brostallicin lending support to clinical development of the drug both as single-agent and in combination [12]. Furthermore, unlike other DNA minor groove binders, mismatch repair (MMR)-deficient cells retain their sensitivity to brostallicin. Since DNA MMR deficiency is common in several tumors, brostallicin has the potential advantage of being effective against MMR-defective tumors that are refractory to several anticancer agents [13]. In this regard, recent data suggest that tumors that are BRCA1 or BRCA2 positive, such as chemo-resistant metastatic triple negative (estrogen and progesterone receptor negative and ERB-2 negative), breast cancer, may be sensitive to brostallicin [14]. The combination of brostallicin and cisplatin may be of particular interest in patients with triple negative breast cancer.

In this study, the brostallicin-cDDP combination proved to be tolerable in most patients, though hematological toxicity was apparent in all cases at all dose levels, non-hematological toxicity was seen in most cases, and all patients experienced at least one CTC grade 3-4 AE. Two DLTs were observed during cycle 1 at dose level 3 (febrile neutropenia with $\mathrm{ANC}<1,000 / \mathrm{mm}^{3}$ and fever $\geq 38.5^{\circ} \mathrm{C}$, and drug related grade 3 fatigue). Dose level $2\left(7 \mathrm{mg} / \mathrm{m}^{2}\right.$ brostallicin associated with $75 \mathrm{mg} / \mathrm{m}^{2}$ cisplatin) was identified as the
MTD of the combination regimen in patients affected by solid tumors. As for activity, no objective responses were observed; however, the $33.3 \%$ rate of confirmed stable disease of significant duration ( $\geq 18$ weeks) documents the antitumor activity of brostallicin-cDDP combination in this patient population with an overall poor prognosis and warrants further evaluation.

Acknowledgments Nerviano Medical Sciences (Viale Pasteur, 1020014 Nerviano, Italy) and Cell Therapeutics, Inc. (501 Elliott Ave., Seattle, WA 98119) are acknowledged for their support.

\section{References}

1. Geroni C, Marchini S, Cozzi P et al (2002) Brostallicin, a novel anticancer agent whose activity is enhanced upon binding to glutathione. Cancer Res 62:2332-2336

2. Lockhart AC, Howard M, Hande KR et al (2004) A phase I doseescalation and pharmacokinetic study of brostallicin (PNU166196A), a novel DNA minor groove binder, in adult patients with advanced solid tumors. Clin Cancer Res 10:468-475

3. Ten Tije AJ, Verweij J, Sparreboom A et al (2003) Phase I and pharmacokinetic study of brostallicin (PNU-166196), a new DNA minor-groove binder, administered intravenously every 3 weeks to adult patients with metastatic cancer. Clin Cancer Res 9:29572964

4. Sabatino MA, Colombo T, Geroni C, Marchini S, Broggini M (2003) Enhancement of in vivo antitumor activity of classical anticancer agents by combination with the new, glutathione-interacting DNA minor groove-binder, brostallicin. Clin Cancer Res 9:5402-5408

5. Simon R (1989) Optimal two-stage design for phase II clinical trials. Controll Clin Trials 10:1-10

6. D'Incalci M, Sessa C (1997) DNA minor groove binding ligands: a new class of anticancer agents. Expert Opin Invest Drugs 6:875884

7. Marchini S, Broggini S, Sessa C, D'Incalci M (2001) Development of distamycin-related DNA binding anticancer drugs. Expert Opin Invest Drugs 10:1703-1714

8. Broggini M, Erba E, Ponti M et al (1991) Selective DNA interaction of the novel distamycin derivative FCE 24517. Cancer Res 51:199-204

9. Baker B, Dervan PB (1989) Sequence-specific cleavage of DNA by N-bromoacetyldistamycin. Product and kinetic analyses. J Am Chem Soc 111:2700-2712

10. Sessa C, Pagani O, Zurlo MG et al (1994) Phase I study of the novel distamycin derivative tallimustine (FCE 24517). Ann Oncol 5:901-907

11. Abigerges D, Armand JP, Da Costa L (1993) Distamycin a derivative, FCE 24517: a phase I study in solid tumors. Proc Am Assoc Cancer Res 34:267

12. Broggini M, Marchini S, Fontana E et al (2004) A new concept in minor groove DNA binder development. Anticancer Drugs 15:1-6

13. Fedier A, Fowst C, Tursi J et al (2003) Brostallicin (PNU166196) - a new DNA minor groove binder that retains sensitivity in DNA mismatch repair-deficient tumours cells. Br J Cancer 89:1559-1565

14. Kiefer J, Shanmugam K, Weitman S et al (2008) Application of cellular pharmacogenomics and systems biology to identify contexts of vulnerability and guide the clinical development of brostallicin. Proc Am Assoc Cancer Res (abstr 920) 